\title{
The Study on the Psycho-social Issues and Challenges of Children with Mental Retardation: A Case Study
}

\author{
Birhanu Moges \\ Department of Psychology, College of Education and Behavioral Sciences, Arsi University, Ethiopia
}

Copyright $\subset 2017$ by authors, all rights reserved. Authors agree that this article remains permanently open access under the terms of the Creative Commons Attribution License 4.0 International License

\begin{abstract}
A lot has been written about the psycho-social issues and challenges of children with mental retardation. The aim of this research is to investigate the impact of psycho-social issues and challenges of children with mental retardation. The study utilized qualitative research tools to explore the deep feelings of the participants. Purposive sampling technique and case study employed as a major study tools. The study used in-depth interview, observation and FGD. The collected data were organized and analyzed through qualitative research approach by using thematic analysis. Findings obtained from the study showed that children with mental retardation are facing different psychosocial challenges like stigma, discrimination, isolation, blame, shame, frustration, feeling of upset, self-insult, loneliness, losing respect, despairing (feeling of no hope), insult, anger and sadness. The study also found that the perception parents of children with mental retardation regarding the causes of retardation was changed from religious beliefs to possible causes of mental retardation as a result of the rehabilitation services. Further, praying, helping each other, reaction formation (insulting who insulted them), developing wishful thinking, and limiting one's interaction were some of the mechanisms explored from this study. The study finally concludes some measures to curb the negative belief systems of the communities towards the children with mental retardation. The study has a great implication for social work practice in the area of policy formulation, advocacy, community mobilization, empowerment, service provision, assessment and research in the areas of disability.
\end{abstract}

Keywords Children, Mental Retardation, Psychosocial, Issues \& Challenges, Family Perspectives

\section{Introduction}

Every father and mothers, who are going to have a child, expect and wish a healthy, intelligent and nice baby. When a child with mental retardation puts his/her step in the science of life, their parents, in their first contact with the child, encounter with a lot of "what to dos" and "what have to dos" Existence of a mentally retarded infant will cause a change in the behavior of family members. Mental retardation, is a disability characterized by significant limitations both in intellectual functioning and in adaptive behavior as expressed in conceptual, social, and practical adaptive skills [21]. Intelligence is both genetically and environmentally determined. Children born to parents with mental retardation are at increased risk of a range of developmental disabilities, but clear genetic transmission of mental retardation is unusual. Although advances in genetics, such as chromosomal microarray analysis, have increased the likelihood of identifying the cause of mental retardation.

Mental retardation is a worldwide problem [15]. Mental retardation occurs once in every 33 people [6]. According to the World Health Organization (WHO), 10\% of the world's population has some form of mental disability and $1 \%$ suffers from severe incapacitating mental disorders [19]. In every age of history, in all cultures, in every stratum of society, there have always been individuals who have had manifested "Subnormal" intellectual functioning. Many of these individuals do not have the ability to manage their affairs with ordinary schooling, and are unable to maintain themselves in the community Coleman as cited in [14]. From the above finding, we conceive that mental retardation is global problem.

In Ethiopia having a child with mental retardation is often associated with feelings of shame and embarrassment, and even in contemporary Ethiopian society misconceptions exist, such as this being a punishment from God. The child can often be viewed as a financial burden for families, many of whom are already financially deprived. Usually, families prefer to keep this kind of children hidden behind doors due to fear of the social stigma attached to it[10]. According to [27] an average of $3 \%$ of the world population has learning and developmental disabilities. Based on this evidence, about 2 million people with disability are estimated to live within Ethiopia. Despite this there still exists a great degree of prejudice and stigma attached towards those with learning 
and developmental disabilities in Ethiopia.

Children with mental retardation face many biopsychosocial problems. The research finding conducted by [21]revealed the psychosocial problems these populations are facing. These are frustration, feeling of shame and guilt, social exclusion, unequal treatment, blame, stereotypes, stigma and discrimination. Further, students who are mentally retarded are sensitive to rejection and are easily hurt by teasing or ridicule [21]. The psychosocial challenges of mental retardation don't stop on the sufferer only but also to their parents. The parents of the mentally retarded children lose hope, even be frustrated and ashamed of their children. Parents do not understand that mentally retarded child could be self supportive member of the family if the necessary parental care, assistance, and encouragement are given. Parents face emotional, social, economic, material challenges while raising their mentally retarded children [9].

Even though the problem is so damaging to both the sufferer (mentally ill children) and their families there are little researches conducted in our country and of them are biological (neurological) oriented and assess other aspects. For example [18] conducted on assessment of adaptive behavior of some children with mental retardation in Ethiopia. Moreover, there is no research on the ways these children should be handled and treated psychologically and socially. It was in light of the above rationale this study was undertaken on the psychosocial problems of children with mental retardation from family perspective.

\section{Statement of the Problem}

The basic tenet of assessment in special education is to identify the abilities of children and fulfill the goals of effective educational intervention service accordingly. In this regard, special educators have to know and internalize the why, how, where and when aspects of assessment that would enable them to properly identify the problem, plan and act on the problem through appropriate and effective intervention. In connection to this subject, mentally retarded children in Ethiopia did not get the due attention. While, the very concept of mental retardation or having birth to a mentally retarded child in Ethiopia have been strongly attached with social stigma. It resulted in isolation and frustration on the part of the families of the retarded person. Mental retardation is a serious disorder. It affects the learning and the psychosocial relationship of the sufferers. Children with mental retardation face many psychosocial problems. Among them are frustration, feeling of shame and guilt, social exclusion, unequal treatment, blame, stereotypes, stigma and discrimination [25]. An empirical evidence conducted by [27] also supports this realities.

On the other hand, mental retardation is not only a problem which affects the ill person but also his /her family members and relatives in particular and the community in general. As result, the families of children with mental retarded undergo through various challenges. Their challenges include psychological, social and economic aspects. The most common psychosocial challenges they face are blame, frustration, stigma, discrimination and social exclusion [27]. The research finding by [18] outlined that the stigma to mentally retarded children goes to educational aspect. He stated that though there are very few of the disabled children in Ethiopia have got the opportunity or access to school, or appropriate education; the case seems more severe for the mentally retarded population. In addition to this [21] research finding on mentalretardation showed that the stigma and discrimination associated with the mentally retarded are the most prevalent challenges of families' of children with mentally retarded. The finding also put forward as the mentally retarded blamed for bringing on their own illnesses, and others may see them as victims of bad fate, religious and moral transgression, or witchcraft.

There are numbers of studies carried out on disabled children. Among prominent researchers, some of them conducted research about children with disabilities in Ethiopia. [22] carried out comparative study of the psychological functioning of children with visual impairment in integrated and special need school setting. She found out that children in the special school were better in their psychosocial function than those in the integrated school. While, [24] saw child rearing practices by parents of children with physical disability. Her major findings were a reasonably long period of breast feeding, inadequate body washing, an emphasis on non- corporal punishment, deemphasis on informal skill training and formal schooling and positive relationship between mothers and guardians and their children with physical disabilities.

The psychosocial experience of children with repaired cleft lip had been studied by [24].The findings were that difference in facial appearance coupled with speech deficits made the children with repaired cleft lip experienced teasing in their day to day lives, which had impact on their social and psychological feelings. Those children Subjected to frequent teasing and insult, social anxiety, feelings of dissatisfaction [18] assesses the adaptive behavior of some children with mental retardation in Ethiopia. The findings indicated that prior to the intervention all children experienced severe deficits in independent functioning skills and other adaptive behavioral characteristics. However, they have made substantial improvements in many of the adaptive behavior aspects mainly in independent functioning, physical development and social maturity. In general, the children's performances show progress and difference in level of retardation.

In relation to this, the research conducted by [9] revealed that some families hide or overprotect a member with mental retarded, keeping the person from receiving potentially effective care or they may reject the person from the family. Moreover, the their finding let out that, even today, as indicated in much of the world, the mentally ill are chained, caged or hospitalized in filthy and brutal institutions.

Mental retardation has implication in the family relationship i.e. it affects the relation among mother, father, 
and siblings.So, from the above literature we can conceive that this study will helps the families' of children with mental retardation through critically understand, recognize and reduce (if possible solve) their problems. [8] also stated that the mentally retarded people are not only stigmatized by non-family members (community) but also by family members. He put forward that the family and friends of mentally retarded person may put up a stigma by association, the so-called "courtesy stigma". Even though the problem is intricate to both the sufferer (mentally ill children) and their families there are little researches conducted in our country and of them are biological (neurological) oriented and assess other aspects. For example [21] "Parental Perspectives on Mentally Retarded Children in Ethiopia the Case of Addis Ababa" he tried to assess the attitudes of parents toward their mentally retarded child, and themselves.

Another researcher named [8] conducted an assessment of adaptive behavior of some children with mental retardation in Ethiopia. Moreover, there is no research on the ways these children should be handled and treated psychologically and socially. Hence, due to the paucity of adequate data on psychosocial problem of mentally retarded children, the need to address the gaps is of paramount importance. What the philosophy and theory of special education state to be implemented are not well practiced in the Ethiopian culture. The society in general and the families of the mentally retarded persons in particular are not well acquainted with what special education and mental retardation are; how to properly identify and handle their children with mental retardation. Retarded individuals have been deprived of their right to get proper attention in education and other socioeconomic affairs and they have suffered a lot from the social stigma attached with mental retardation and from the impacts of lack of awareness by the society. To this effect, it was imperative to undertake a study to investigate the psychosocial problems of mentally retarded children. It was in light of this understanding; this study had been undertakenin Adama City Administrative No.2 Primary School.

\section{Research Questions}

To address the issue of the study, the following basic questions were stated:

1. What are the psychosocial challenges/problems mentally retarded children facing?

2. How do mentally retarded children families perceive towards their mentally retarded children?

3. How do the families of the mentally retarded children respond (communicate) to the needs of their children?

4. What mechanisms should be taken to reduce psychosocial challenges/problems mentally retarded children face?

\section{Significances of the Study}

The absence of identification instrument and the lack of understanding of mental retardation as well as that of adaptive behavioral characteristics of the children by the parents, highly limit the early identification and arrangement of the possible services for the children according to their need. This in turn prohibits the opportunity of enabling the children to help them to the maximum potential possible. Therefore, a research study directed toward such topic is hoped to deserve significance, because it could contribute for the solution of the currently existing problems mentioned.

Further, this study will helps the family by enabling them understand mental retardation scientifically and treat their children accordingly. In other word, by exploring the psychosocial challenges/problems of mentally retarded children and the way the community responds to such problem, the family will have the chance to properly understand the situation of their children and be able to provide necessary services. As a result, the mentally retarded children may get benefits through obtaining appropriate support from their family (caregivers).

This study finding benefits also goes to teachers, mental health professionals such like Psychiatrists, psychiatry nurses, social workers, psychologists and other health professionals who are working in the hospital and other health institutions by offering information about the psychosocial problems of the mentally retarded children are facing. As a result, they enable them to understand community related problems and the interventions too. Likewise, it can also offer a clue for policy makers to advocate and lob about the problem. It also gives insight to government and nongovernmental organizations for the importance of designing possible intervention program for the mentally retarded and the centre workers also sees the gap between the objective and its implementation. Motivate concerned bodies to give attention to the problems and play an active role in the service provision activities.

\section{Delimitation of the Study}

The nature of the topic and area as well as the method of the study seem to be broad and comprehensive which demands a lot of time, budget, facilities, material and trained human power. During the planning stage, although not to the demand of the study, attention was given to the respective variables. This study was delimited to assess the major psychosocial problems that mentally retarded children are facing. The reason to focus on this aspect was most of the mental health studies conducted in Ethiopia are patient focused and biological oriented i.e. they give little attention to the psychosocial problems of mentally retarded children.

Hence, the scope of the study was delimited to Adama city Administrative, No.2 Primary School which promotes special education for the respective children. The main reason to conduct this study on this area was the area conduciveness to get the estimated number of respondents necessary to obtain relevant data and no study conducted in this area. However, the research findings cannot be 
generalized to include other service providing centers in the country as well as the experience and reactions of mentally retarded children throughout the country.

\section{Objectives of the Study}

The main objective of this study was to explore the psychosocial challenges/problems of children with mental retardation from a family's perspective. The specific objectives of this study were:

- To explore the psychosocial problems mental retarded children are facing.

- To assess the perception of mentally retarded children families towards their mentally retarded children.

- To identify the way the families of the mentally retarded children respond to the needs of their children (communicate).

- To assess mechanisms which should be taken to reduce psychosocial problems mentally retarded children are facing.

\section{Materials and Methods}

\section{Design of the Study}

The study used a cross- sectional descriptive research. Researchers observe at one point in time. Qualitative methodological approach involves that do not attempt to quantify their results through statistical summary or analysis. Qualitative research seeks to describe various aspects about behavior and other factors. In qualitative research data are often in the form of descriptions, not numbers. According to [13] the descriptive method of research is vital to gather information about the present existing condition. In addition, since this study will focus on exploring the psychosocial challenges of children with mental retardation, the two methods are the most appropriate to use.

The study utilized qualitative research tools in order to explore the deep feelings of the participants. Qualitative methods helps to explore the meaning individual or group ascribe to a social or human problem which involves relatively small number of participant and it will lead researcher to assess the feelings, values and perception of families toward mental retarded children. Thus, to identify the major different psychosocial challenges that affect the life of children with mental retardation, FGD and semi-structured interview were developed to fit the situation of the study area and to collect all the necessary data.

For this specific research, the researcher taken up case study method to describe and explore the impact of rehabilitation services on the psychosocial condition of children with mentally impaired at Adama city Administration, Adama No.2 Primary School. Case study is used in many situations to contribute to our knowledge of individual, group, organizational, social, political and related phenomena (Padgett,2008). Case studies involve an in-depth examination of a single person or a few people. The goal of the case study is to provide an accurate and complete description of the case.

The principal benefit of case studies is that they can expand our knowledge about the variations in human behavior. Although experimental researchers are typically interested in overall trends in behavior, drawing sample-to-population inferences, and generalizing to other samples, the focus of the case-study approach is on individuality and describing the individual as comprehensively as possible. The case study requires a considerable amount of information, and therefore conclusions are based on a much more detailed and comprehensive set of information than is typically collected by experimental and quasi experimental studies.

\section{Study Area}

Adama is a capital city of Eastern Shoa Zone of Oromia regional State. It is located at $8.54^{\circ} \mathrm{N} 39.27^{\circ} \mathrm{E}$ at an elevation of 1712 meters, $99 \mathrm{~km}$ southeast of Addis Ababa. The city sits between the base of an escarpment to the west, and the Great Rift Valley to the east. This study is conducted in Adama city Administration, No. 02 Primary School found in Kebele 04.

Adama No.2 Primary Schoolis the specific study area of this research. It established in 1886 E.C and give service for mental retarded children since established. It is the only schools in Adama which try provide education for mental retarded children. There are 22 students mental retarded children found in the school and get education service. But school gives less treatment and care for his student because of limited professional man power on treatment of mental retardation. The school have uneducated and unprofessional teacher who give care unknowing their need.

\section{Sample Size Determination and Sampling Techniques}

To select the participants the study was made use of purposive sampling technique. The reason why the researcher chooses purposive sampling was that, for the sake of meeting directly children who are physically impaired in the rehabilitation centre. The idea behind qualitative research is to purposefully select participants or sites that will best help the researcher understand the problem and the research question [11-13]. Purposive sampling is one of sampling techniques in qualitative research that is deliberately made to select respondents based on their natural ability to give the required information [19].

The target population of this study was the family of children with mental retardation who were selected purposefully. All the families of the children with mental retardation who were found in the data collection site at data collection period were a sample of the study. The sample size in a qualitative case study research will be about four to five 
cases [11-13]. While, in this study they were fourteen (14) in number. Accordingly, by using purposive sampling technique, the researcher conducted an interviewand FGD with six (6) and eight (8) families of children mental retardation respectively. Hence, a total number of 14 participants were used as the sample of the study.

\section{Data Collection Instruments and Procedure}

Data collection is one of the most important variables, which attribute to obtaining relevant information effectively. Data collection in qualitative research requires much time, labor, knowledge, skill and finance [12 \& 13]. Being cautious of these and related factors the researcher planed and proposed accordingly. This study gathered data using primary form of collecting data. Four basic data collection instruments were used to secure the reliable and adequate information. These were in-depth interview, focus group discussion, observation and document analysis.

Interview: The researcher had conducted face to face interviews with participants. These interviews involved unstructured and generally open ended questions. The interview guide was prepared by the researcher based on the general research question and the specific objectives. In-depth interview was undertaken with four groups; children with mental disabilities, parents of children with physically impaired, social workers, with the Physiotherapist and with the manager of the Adama city Administration, No. 02 Primary School. The interview was agreed in Amharic language except interview with physically impaired children, which were carried out in both Amharic language and Afan Oromo, with the consultation of language experts regarding the agreement on both forward and backward translations. The translations were made mainly to avoid language barriers and facilitate the process while the respondents were responding to the interview questions.

Focus Group Discussion: Focus group is extremely useful in providing qualitative data which gives an insight into attitudes and perceptions difficult to obtain using other procedures [11-13]. So it was engaged to develop data gathered from children with mental impairment, from parents of children with physical impairment, social worker, from physiotherapist and from the rehabilitation centre manager.

Observation:In combination with the process of in-depth interviews, observation was also used as an additional instrument of data gathering technique. The main advantage of this observation was to understand the expression, feeling and perception of participant's reaction. According to [11] through qualitative observations it is possible that researchers can take field notes on the behavior and activities of individuals at the research site.

Document Review:The researcher used different written documents to supplement the study. Such as annual reports of the rehabilitation centre, broachers and different photographs which had necessary information for the study.

After all the above activities conducted well, the next procedure that done was data collection. First, permission (ethical approval) from the school administrators was asked. As soon after the researcher got the permission, the researcher briefed for each participants about the purpose of the research before the interview and FGD. After they were provided with the necessary information's including ethical considerations (gaining consent, expressing their freedom to stop in the middle of the session if they were not comfortable with some issues, the right of the interviewer to paraphrase and ask questions while he/she need for clarity, confidentiality and data Protection), the Amharic version interview and FGD questions asked for six and eight children with mental retardation families respectively.

\section{Data Analysis}

In analyzing data the study used three procedures that were organizing, summarizing and interpreting the data. After collecting the data in the above different data collection instruments, they were categorized into major idea for their specific cases to shape the basic research question. As a result, this helped the researcher to summarize the data successfully to the case. Then, the organized and summarized data was discussed or interpreted carefully. Interpretations were concerned in reflecting the words and acts ofthe data source and the researcher's personal judgment were used to strengthen the findings.

\section{Ethical Consideration}

The analysis as well as disclosure of material facts conducted in an ethical and strictly supervised procedure. Strong ethical considerations were attended in the study, clients were requested for their permission on the interview and the use of information confirmed as to only the study purpose. Although no consent paper signed from both parties, there were many works done to protect the confidentiality of the respondents. Among them, they were oriented as they are free either to stop or to talk in the middle of the interview, refuse to disclose those issues the respondents which they consider private and so forth. The interviewer also told his rights such like paraphrasing the questions while he need for clarity, not speak his private issue and so forth.

\section{Results and Discussions}

This section presents the findings of the study. It has two main subsections. First, the background information's of participants was presented. The second, findings obtained from the qualitative data were presented. 
Table 1. Respondents' Background Information ( $\mathrm{N}=14)$

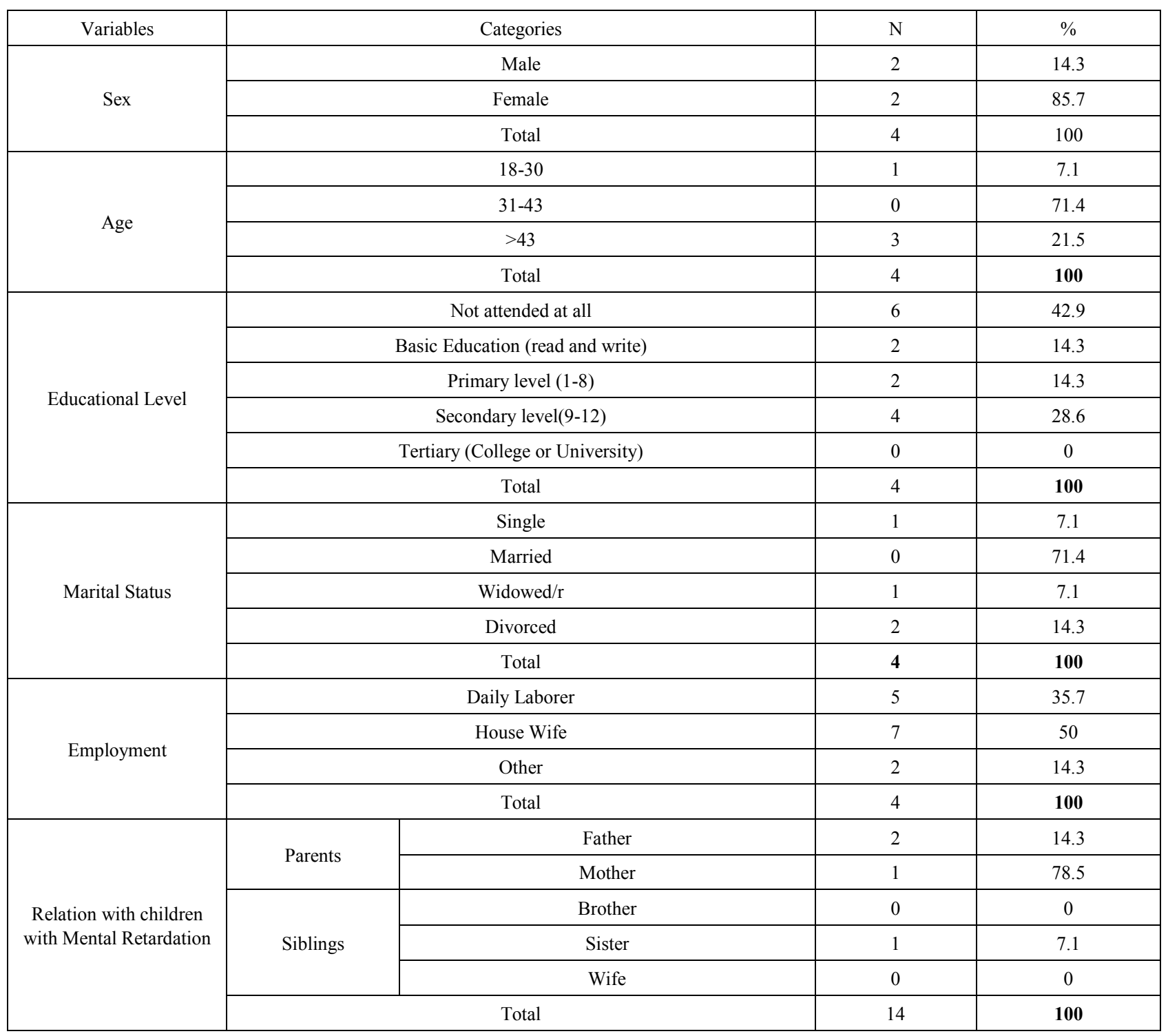

Fourteen (14) families of children with mental retardation were participated in this study. Among these, 2(14.3\%) were males while the rest $12(85.7 \%)$ were females. As Table 1 above shows, of the total fourteen respondents, 1( $7.1 \%)$ participants' age ranges from 18-30 years, 10(71.4\%) of respondents' age range from 31-43 and the rest $3(21.5 \%)$ was above the age of 43 . With regard to their educational level, 6(42.9\%) were not attended at all, basic education (read and write) $2(14.3 \%)$, primary education $2(14.3 \%)$ and the rest $4(28.6 \%)$ were followed secondary level. Concerning the marital status of participants, $10(71.4 \%), 2(14.3 \%), 1(7.1 \%)$ and 1(7.1\%) were married, divorced, widower and single respectively.

Finally, regarding the care givers relation with the children with mental retardation, 11(78.5\%), 2(14.3\%) and 1 (7.1\%) were mother, father and siblings respectively. 
Table 2. Background Information about the Children Mental Retardation

\begin{tabular}{|c|c|c|c|}
\hline Variables & Categories & $\mathrm{N}$ & $\%$ \\
\hline \multirow{3}{*}{ Sex } & M & 8 & 57.1 \\
\hline & $\mathrm{F}$ & 6 & 42.9 \\
\hline & Total & 14 & 100 \\
\hline \multirow{5}{*}{ Age } & $5-10$ & 0 & $\mathbf{0}$ \\
\hline & $11-16$ & 14 & 100 \\
\hline & $17-22$ & 0 & 0 \\
\hline & $>22$ & 0 & 0 \\
\hline & Total & 14 & 100 \\
\hline \multirow{2}{*}{ The onset of the illness } & At Birth & 14 & 100 \\
\hline & After Birth & 0 & 0 \\
\hline
\end{tabular}

Of the total fourteen (14) children with mental retardation, $8(57.1 \%)$ were males and 6(42.9\%) were females. As Table 2 above shows, participants' age ranges found between 11-16 years(100\%). With regard to the onset of the illness, all children acquire this illness at birth.

The semi-structured interviews were held with six people. Among them, two were males and the remaining four were females. The finding of this study obtained from semi-structured interview presented and describes as follows:

Community Understands about Mental Retardation: Regarding this questions, the data obtained from the six participants were similar. They revealed as their community attitudes towards mental retardation, as participants stated, is differ based on some factors such as level of literacy and culture. For example, with regard to literacy, the interviewees stated as the literate (not all but the majority) treat them positively and they also told to the researcher as the opposite was true. The participants of interviewees of this study offered their communities definition/understanding of mental retardation, which they defined it as an illness which makes the persons' thinking ability totally dysfunction, in their language "out of use", is transmitted and untreatable. However, they also disclosed as there are people who don't see on such way. Moreover, the participants revealed as youngsters their peers are the most threatening age groups who are stigmatizing children with mental retardation.

Concerning the causes of mental retardation, the participants stated as their communities attributed it with the different beliefs. These were, the curse from God, demon possession or by evil spirit what they call in their language "likefete", "yebetetata", "Bemetete", tears of person on the family, "ergoze hone tsebelmetetate", hereditary, "yaletegeberegebre", economic problem-poverty and so forth. This perception is before their children get the rehabilitation service. Presently, however, their perception is changed and they understand that the causes for physical impairment are disease and accident. So, the parent's belief changed from false notion to possible factors after they bring their children into the center and get counseling and the awareness created by the social workers.

The foremost cause of disability was infectious disease such as tuberculosis, trachoma, otitismedia, meningitis and parasitic disease. The second major cause of disability was war, trauma or accident. The third most common cause of disability was congenital and non infectious disease such as epilepsy [27].

Parental reactions by having a child with mental retardation: The result of this study indicates that, when parents of children with mental retardation realized that their child is mental retarded, they react in bad situation and faced high psychological problem such as hopeless, sad and disappointment. In relation to this, disappointment, anger and guilt has identified as three major emotional reactions and are common among parents when they came to realize that the child is physically impaired [26]. According to [15] after the discovery of the problem, these reactions are likely to occur soon. Guilt feelings arise from the need of parents to deny that they are angry at child.

The Psychosocial Conditions of children with mental retardation: Children with mental retardation were suffering a lot in their psychosocial condition they sense shocked in the way how people perceive about their impairment. Children also develop low self esteem; this is because their peers didn't allow them to play with. In the school, those retarded children have no the exposure to participate in mental sport activities.

In relation with this [26], the reaction of parents and care givers as well as teachers and students do influence in the social and emotional behaviors that children exhibit in school, at home and in the community. The social and emotional behaviors manifested by children with mental retardation are functions of the factors. Most psychologists agree that the development of healthy social and emotional behaviors depend to a large extent on children's participation in positive interactions with and positive feedback from care takers.

Sources of psychosocial support: Participants of the study did not access any psychosocial support from professionals or other sources after diagnosis process. Providing detail 
information about children with mental retardation is one form of psychosocial support. As families know more about children with mental retardation, its impact on the family wellbeing might change to minimal level. Low level of awareness

about children with mental retardation and the long process of the diagnosis have complicated the life of the families. Participant number 5 presented inadequacy of psychosocial support in some medical centers in the following way. She says:

\section{I went to a physician for medical examination of my son. After thorough examination, he gave me medical certificate only. He didn't say anything about the case of mental retardation. I get confused since I didn't find a solution to my son problem. Then I decided to send the medical certificate to a physician whose is my relative. He read the paper and provided me with detail information of mental retardation (Participant number 5, age 28).}

In the diagnosis process, out of the six participant's only one participant acknowledged the provision of psychosocial support from a physician. She says:

\section{I never heard about mental retardation. Naturally, I am a person like who consider situations as simple thing. Not only for the case mental retardation but also for my early pregnancy my response was taking it as a simple thing. The physician who involved in the diagnosis process provided me detail information about mental retardation in relation to care and management. He also assured me that if I provide proper care to my daughter at the age of 10 my daughter will have noticeable change. I promised to celebrate if this happens to my daughter. His expectation was correct, since my daughter had noticeable change I have celebrated her 10th year birth day at hotel by inviting 30 individuals (Participant number 1, age 37).}

Attitude of the Community towards Children with Mental Retardation: Data gathered from all the interviewee shows the existence of negative attitude of the communities especially among peers towards children with mental retardation. They revealed as these negative attitudes of the community manifested on their beliefs they do have on and during interaction they make with them. The followings are some of the beliefs and ways of interactions of the communities do have towards children with mental retardation which were outlined from the interviewees:

The participants expressed thatwhen they see individual with mental retardation they run, this interaction pattern is common among person with same age. These individuals also initiate them to aggressive "Yetenekusutale". Almost all the communities see them in surprise " $000000000 "$ ".
They also revealed as they don't want to: be seen with them, make friendship with them, and play with them. Moreover, they revealed that they don't greet them even at school although they can give response.

Furthermore, most interviewees stated as this negative attitude of the communities does not stop only on children with mental retardation but also to their family members.

Psychological Challenges: As stated by all interviewees' children with mental retardation are facing the following psychological challenges. These are: being upset (sadness) "Am I Not Human Being", tearfulness (cry), feeling of hopelessness, feeling of upset, inferiority feelings, frustrations and so forth.

Social challenges:The social challenges, as outlined from interviewees', children with mental retardation are facing are:they want to use their labor, they motivate them to learn bad behaviors they are doing(e.g. abuse drugs), they isolate them, unequal treatments, they insult them [7], harassments, peers don't want to play with them, they don't want make friendship and even beating them especially by their peers and so forth.

Managing the Psychological and Social Challenges: The mechanisms, as revealed by the interviewees, employed to reduce the psychological and social challenges children with mental retardation are facing. The following listed were some of them identified among the interviewees of this study.

Pray to God or "Do'a": "Tearing to God"), having a belief of "all were by him, God knows" were the most frequently stated mechanisms.

Offering love \& care: for example one of the interviewee stated that "they will lead better life if we love them although their problem is dangerous". Although there were no significant helping institutions sited Church, Mosque and family were the most frequently put forward institutions which they offered help for this people. The support they gave was emotional.

Suggestion to be done at individual, family level (collaboratively), community or societal (government) level to reduce (if possible to solve) the problem. The interviewees of this study suggested some actions which should be taken to reduce (if possible to solve) this problem. These were:

Individually: Since the problem affects the life of everyone, as they stated, they suggested as every person need try to know about the problem through reading different materials. This in turn will help them to reduce the negative attitude they do have towards children with mental retardation and as a result to treat them with due care.

At family level: If there is an open discussion in family, as they stated, it will reduce it to minimal level and accordingly to provide the necessary care and support. They also stated its emotional benefit it does for the family members. In line with this one of the interviewee stated that "We all are illed due to her". This implies that family should work together to deal with problem.

At governmental level: The interviewees of this study 
stated as this problem is not only a problem of an individual but also societal in such way that it affects the life of other and the development of a country. Thus, the following were some tasks they gave for it. These were financial subsidy, moral support, distributing different services that are vital to them and safeguarding the rights of children with mental retardation.

Participants of the FGD were eight in number. From the FGD like the semi-structured interview, this research tried to explore the experience and views of the interviewee in relation to: the psychosocial challenges (i.e. stigma, discrimination, stress, frustrations and other burdens) that children with mental retardation faced and the mechanisms to reduce the challenges. The researcher found a similarity in findings between the semi-structured interview and FGD. In order to present the findings easily and in understandable manner, like he did in the case of semi-structured interview, the researcher opted to put the main issues as topic and then present and discus the issues explored from the study.

Community Understands about Mental Retardation: Like the participants of semi-structured interview did, the participants who participated in the FGD of this study offered their communities definition/understanding of mental retardation, as most stated, which they defined it as an illness which makes the persons' out of use and which could not be treated. Among the eight participants, three were agreed as their communities have awareness about mental retardation. However, all participants including this three revealed as their communities do have negative attitudes towards mental retardation, children with mental retardation and to their family members. To justify their idea for the existence and prevalence of such attitudes towards that people, they forwarded some ideas. Firstly, no one can recognize him/her as human being, don't want to go or do any activities with him/her and at large they want to fulfill their own needs, "Yetekemubatal" as one of the participant revealed. The "normal" people attribute their mistakes on them because they children with mental retardation couldn't express and defend their feelings like them. The other was, according to them, they (their neighborhood, at large the community) were reluctant to help them in the time of crisis. However, all the participants disclosed as there are people who helped them (but too few).

Moreover, the participants expressed that these communities' challenges/threats don't stop only on the children with mental retardation but also to their families' members. Regarding the causes of mental retardation, all participants uncovered as the view of their community differ. The following were some views of the community regarding the causes of mental retardation which had been outlined by the participants of this study. These were: God's punishment-"A response for one's misconduct/breaking of God's commandments". Possession by evil spirit, what they called "likefet". Genetic or hereditary

Psychosocial challenges of Children with Mental Retardation: Concerning this issue, all the participants of the study stated as their communities hold negative attitude to and low interaction with children with mental retardation. The below listed behaviors, as outlined from the participants, were some of the ways which signify the negative attitudes of the communities towards children with mental retardation. These were:

Isolation: "They don't want to go/work with them. They don't have trust on them. No responsibility given for them even if they do have potential.

No audience: It is to mean that no one who can hear or give value to their ideas or sayings. They are degraded on all aspects of their life.

Blame :The participants put forward as their children with children with mental retardation have been insulted. They revealed that this may takes place nonverbally.

The labeling of "Ibidu, Duda". : Most participants of the study disclosed as this negative attitudes toward children with mental retardation is not only from outside but also from the family members too (e.g. related to this, one of our participant shared one case which he faced from their home, "one guest asked my brother (mentally ill children) about the life style of the city, when he tried to answer the question, our elder brother stopped him, by saying 'why you ask him?, he don't know nothing. Ask me". Although all participants agreed as such attitude and interaction pattern (psychosocial challenges) exist in the studied community there were individuals who have positive attitude and are helping them.

In sum, all the participants have noted that their communities do have negative attitude and low interaction towards children with mental retardation. Based on the above findings, the researcher noted as children with mental retardation are suffering from innumerable psychosocial challenges such as stigma, discrimination, isolation, blame, fear, shame, hopelessness, frustrations and being upset.

Managing Psychosocial Challenges: The participants of this study revealed as they use different psychosocial management styles in response to such above mentioned challenges. The following were some:

- $\quad$ Praying to God

- Thiswas the most repeatedly stated mechanisms used by all the participants the study.

- Reaction formation( insulting them)

- Developing wishful thinking,

- Limiting ones interaction.

- Let them to join special schools

- Giving verbal praise and hope

- Regarding the kind of support they got, as they stated, was emotional.

Things to be done at various level to reduce (if possible to solve) the Challenges: Participants of this study have suggested some ways to solve this problem. Their suggestions lie at three levels i.e. individually, family and governmental.

At Individual level:They suggested as every individual should look him/herself since mental retardation can occur 
on everybody. They disclosed that improving ones understanding about mental retardation and related issues would help a person to change oneself, this could be achieved through many ways such like reading materials which give clue about the problem. They also disclosed as teaching others (e.g. friends) could help others to know about the issue and change their attitudes.

At Family level:An open discussion about the issue and family support (helping each other) were some of the suggestions stated by the participants. Treating them equally and giving due respect as we do for others.

At Governmental (societal) level:All the participants of the study has put forward as government had not work or didn't give attention to this group of people (children with mental retardation) and their family members. Thus, they suggested the following tasks which should be done by it.

Giving education to create awareness about the problem using different meanness like mass media, community based education ("it can use the model which has been working on HIV/AIDS" as it has been said by one of participants).

Help economically-beside the behavioral change, the participants suggested if the government work in subsidizing financial costs to the children with mental retardation. This idea was highly supported and suggested by the most participants.They also associated it with issue of human rights. Regarding this, the participants expect the government to work to protect the rights of this group of people.

\section{Discussions}

The purpose of the present study was to explore the major psychosocial challenges that the children with mental retardation are facing. Based on the findings presented in the analysis part, a discussion was made in line with former studies conducted in the area here under. The results show that the major needs of the child are related to basic needs, education, health care and security, and that families need socio - economic support. Other challenges faced by the families are discrimination, interpersonal relationships and concerns for the future. A child with mentally retarded is a heavy burden for the family. There is a great need for support from the community and society.

As indicated in the finding of the study participants have little knowledge about mental retardation. In relation to perception, participants of the study forwarded their perception about mental retardation as life incident happening to anyone, something given from God (punishment and as incurable problem). According to [6]mental retardation is one of the most common developmental disabilities affecting people of every race, ethnic group, and socioeconomic background. The low levels of awareness about mental retardation in all participants of the study imply that as none of the participant perceived mental retardation as developmental disability.
The only understanding shared with some of the participants is as it affects every people. Perception of participants forwarded in the findings as gift of God and incurable problem are not supported by literature. The finding about knowledge and perception in general indicate that participant's low level of awareness and unclear perception about mental retardation.

This study revealed the major psychosocial challenges children with mental retardation are facing. These challenges are various like frustration, sadness, insult, harassment, stigma, discrimination and isolation because of negative attitudes, misunderstandings, and negative stereotypes towards mental retardation. A study conducted by [4]support this finding and it stated that person with mentally retardation carries such a stigma, discrimination that to admit its presence in a family is like revealing a shameful secret. As a result, very little is done for retarded children or adults, apart from locking them away. And yet the problem is widely prevalent, and millions of people suffering from it receive no professional attention or care.

About one - third of participants in this study claimed that they had perceived thepresence of mentally retarded in their families positively. This perception has repercussions on themanagement of the child. However, their claim was difficult to substantiate. During theinterviews some of the participants who said they had perceived the birth of the child intheir families positively later expressed negative feelings about mentally retarded in their family. Theycomplained bitterly about tasks relating to the care of their charges. This contradiction maybe explained by the fact that the participants wanted to answer "correctly"; many arereligious and having a child with MD is seen as God's will, which has to be accepted. Some studies have shown that very often parents have a negative attitude towards their children with disabilities [25].

Challenges of families as forwarded in the finding session indicate that they whole family system has been impacted by mental retardation. In the psychological aspect, the entire participants have experienced stress, and anxiety. [21]stated that mental retardation other than other childhood disabilities is a more stressful condition for families. The mothers of children with mental retardation also described situation as stressful and experiencing more depression. Father's also reported higher level of stress [19]. The findings from the entire participants indicate that stress and anxiety are the common psychological challenges to families living with a child diagnosed with mental retardation. Initial factors that stress families' as told by participants are inability of children to express their feeling, future life of their child, feeling of sorrow and who will take care if something happens to me are forwarded in the finding session.

The problem of interpersonal relationships in managing disabled children and adolescents needs to be highlighted. [3] Found that interpersonal relationships are central to the quality of care for patients. The author noted that the technical aspects of care received less recognition in care 
outcomes in comparison with interpersonal relationships. Parents of children with mental retardation face such like psychosocial challenges: loss of self esteem, shame, ambivalence, depression and so forth. Likewise the study finding of [9] also revealed as the parents of the mentally retarded children lose hope, even be frustrated and ashamed of their children. This (the current) study finding also consistent with the above two finding. Based on the above points the researcher understood that the communities where by the interviewees of this study live in, did have negative attitudes towards mental retardation. The researcher also noted as there are people (among the community) who have good understanding about it.

As forwarded in the finding session participants social life and participation in social events limited. For all participants the reaction of the community matters to be actively involved in social life. In attending public places one participant told that low level of awareness about mental retardation is the main factor to experience social isolation or discrimination and embarrassment. This finding of social challenge of mental retardation is related to [25]study indicating that the society had a difficulty to accept a child with mental retardation. The low level of probability to get acceptance from the society exposes parents to experience social stigma and embarrassment associated with inappropriate behavior displayed by these children [19]. Preference to isolate one self and fear of taking child in public are other social impact forwarded in the finding session. One of the participant told that neighbors have isolated us; they show false sympathetic gestures rather than love, care and support. In public places also due to the behavior of my son I feel shame and afraid of to attend public events and family affairs. The finding presented by this participant goes in line with literature of [16] indicating that families have fear of their children's behavior and act and parents prefer to isolate themselves instead of facing the frustration of taking their child in public [1].

The special education needs of children with MD seem to have received very littleattention from society. The government has put little effort into establishing schools formentally disabled children. Education was one of the social difficulties experienced by manyof the families in this study. The learning environment was described to lack motivation forthe disabled child. Many families expressed concerns that their children were not benefitingfrom schooling. These children need well - programmed sessions to benefit them. This requires teachers who are well trained and equipped to teach. The education of should include areas of life skills from early life [1]. Also, it is doubtful whether disabled children undergo mental assessment prior to admission to school - another area to be addressed.

The mechanisms that the families and children with mental retardation used were, the other findings obtained from the present study. These were pray to God ("tearing to God") or Do'a, being silent, helping each other (self-help group, discussing about the issue with family and close relatives), rethinking the situation in a positive way, reaction formation (insulting back), developing wishful thinking, teaching them about the issue for those who are willing, limiting one's interaction, and telling as the problem may also occur on them and so forth. This study finding is consistent with [17], which stated that the most frequently used and considered mechanisms that family and children with mental retardation are such like, looking for information, learning experience, acquiring social support, escape/avoidance and having positive hope. Thus, this research finding is reliable the above mentioned researchers findings.

In the finding session as forwarded by participants accepting the situation, changing the meaning of mental retardation to a positive, blaming God or themselves, feeling of sadness, changing hopelessness thinking to hopefulness, forgetting and considering situations as beyond our control are coping mechanisms presented. This finding is in line with [19]Emotion focused coping function to change either the way situation is attended to (by vigilance or avoidance) or the meaning to oneself of what is happening. The other finding presented by one of the participant is taking actions or measure by focusing on the problem. As told by her money is the major challenge. To find money I look for every alternative source of income and solve the problem. [16] Problem focused coping tries to change the situation by acting on the environment. Situations which are controllable by action are dealt by focusing on the problem.

The researcher also noted from this study that children with mental retardation and their families employ different management styles to reduce the psychosocial challenges they face. The participants employ these mechanisms especially when the frequencies of the challenges become tense and usual.

\section{Conclusions}

The main objective of the present study was to explore the major psychosocial challenges that the children with mental retardation are facing. Fourteen participants were selected for this study by using purposive sampling. Among these, 2(14.3\%) were males while the rest $12(85.7 \%)$ were females. Among fourteen, six were for semi-structured interviewee and the remaining eight were for FGD.

Findings from both FGD and semi-structured interviewee data show as children with mental retardation are suffering from the stigma, discrimination, blame, isolation, insult, frustration, shame and other psychosocial challenges due to misunderstandings, and negative stereotypes and attitudes surround mental retardation.

This study also explored the mechanisms that the families and children with mental retardation employed in response to the psychosocial challenges they face. These were praying to God ("tearing to God") or Do'a, not going out of homelimiting ones interaction, reaction formation( insulting back), 
discussing about the issue with family and close relatives, and so forth.

Teachers were also requested to give their view on what is expected of parents, school, society and government to improve the handling of the intervention program. According to their response majority of them said that,

Parents should be given some sort of orientation on mental retardation (the concept, Social psychology, etiology, prevention and intervention), handling the children and in collaboration with others etc.

Parents should give affection to children with mental retardation equally to the other siblings/if not more.

Parents should cooperate with schools and others who work for the good of the children under consideration.

Orientation should be given to the society on mental retardation and persons with mental retardation.

Schools have to be aware of the condition and strengthen their effort to establish conducive atmosphere to run the intervention program smoothly.

The government should give more attention to offering proper training to teachers and the children so as to make the children's future careers easier for independent functioning.

In the statements of the state policy, the government should give more emphasis to the training and placement of persons with disability at various levels. Some form of incentive or encouragement should be given to the teachers of children with mental retardation.

The study has described family challenges of caringmentally retarded child in relation to psychological, social, marital, economic and sibling aspects. It also described coping mechanisms employed in relation to challengesfaced in different life aspects and source of psychosocial support.Based on the findings of the present study, the following conclusions were made:

Most of the families in the study are not aware of mental retardation before the diagnosis process. In the diagnosis process also provision of psychosocial support is limited. The diagnosis process is also tiresome and long as most professionals in the medical setting were not aware of mental retardation. The family is facing a multifaceted challenge in and after the diagnosis process. The complication related to tiresome diagnosis process and lack of psychosocial support risked family to experience stress, shock, and anxiety.

Families under study caring a child diagnosed with mental retardation are facing social isolation and discrimination in their social life. In public places also since the community point out finger to families and gossip each other, most families are in fear or afraid to appear in public. The participation of families in social life is limited by caring a child diagnosed with mental retardation.

Children with mental retardation are facing a double burden. The first is from the illness itself and the other is psychosocial challenges (e.g. frustration, sadness, insult, harassment, stigma, discrimination and isolation) they are confronting because of negative attitudes, misunderstandings, and negative stereotypes towards mental retardation.

Thus, the findings of the present study witnessed that, children with mental retardation are loaded down by the above mentioned psychosocial challenges.

This study also explored the mechanisms that the families and children with mental retardation employed in response to the psychosocial challenges they are facing. These were praying to God ("tearing to God"), not going out of homelimiting ones interaction, reaction formation( insulting them), discussing about the issue with family and close relatives, and so forth.

Thus, the findings of the present study indicated that the families and children with mental retardation are suffering from a number of circumstances that erode their strengths and resources. Being burdened by various psychosocial crisis and challenges, their management skills are minimum unless they receive extra professional support.

As the study indicates, children with mental retardation had faced challenges in psychological and social wellbeing before they joined the rehabilitation centre. However, with this regard social workers should alleviate their problem with the collaboration of multidisciplinary professionals to bring holistic life change. Social workers are responsible for the organization and awareness creation about mental retardation to the community, Governmental Organizations, NGo's, for different institutions (religious, schools, hospitals etc), associations and stakeholders to participate in rehabilitation programs. In addition to this, social workers should engage in advocacy, community mobilization, empowerment and professional service provisions.

Disability is still hidden agenda especially in the rural and some urban parts of Ethiopia and still it has been given lesser attention. People are not well aware about even the issue. As indicated in this specific research there is high level of stigma and discrimination, less social relationship with non disabled peers, lake of inadequate treatment and no preprevention activities. So, these bother the psychosocial condition of children with mental retardation before they have got rehabilitation services. Therefore, this research can help to consider those mentioned points to be taken into further social science researches. For illustration, a research can be conducted on the issue of pre prevention and causes of physical impairment. The study also gives away to similar researches in other types of disabilities.

The findings of this study in line with the evidences found by other researchers in the field help/ have important practical implication to such institutions; health, educational and so forth. It helps educational and health institutions to accommodate their needs and do in favor of them. It helps policy makers to make advocacy and initiate to implement the strategies regarding this issue (the finding pointed out as the rights of children with mental retardation violated by the community they are living in). Moreover, the study has practical implication to those NGOs, GOs and civil societies who are working on this target groups. 


\section{Recommendations}

This section tries to describe the recommendation of the study conducted for socialwork practice with emphasis to challenges of families living with a child diagnosed with mental retardation experienced by parents. Nowadays, as it is obtained in the present findings,children with mental retardation as well as their families are facing stigma, discrimination, isolation and other psychosocial challenges due to the misunderstandings, and negative stereotypes and attitudes surround mental retardation.

"Mental Retardation" is not a disease and can be rehabilitated. This fact must be brought to light through media by the

Government, which will reduce the problems of parents with Mentally Retarded Children to a maximum extent.

More number of Early Intervention Centers and Rehabilitation Centers should be set up by the Government in order to reduce the social problems faced by the parents of Mentally Retarded Children. One of the most important areas is to give counseling to the parents with Mentally Retarded Children. The counseling will help them to reduce the level of social problems and to gain knowledge about their Child's future and also about the help available from the Society and Government. For this purpose Government should appoint qualified counselors at all special schools and also in elementary and middle schools.

Families living with a child diagnosed with mental retardation are living in stressful situation. The community's reaction to a child diagnosed with mental retardation is firing back its impact on families. In order to brighten the hope of families community is at the center to bring change of attitude. The major change should begin from the community. Changing the attitude and perception of the community through organizing awareness raising campaigns in cooperation with different stakeholder is the main activity in social work practice. Preparation of pamphlet, blogging on newspaper and web sites can be used as an alternative approach in reaching the community. The large community at country level can be addressed through extensive media coverage about mental retardation involving government and non-governmental bodies. The findings of the challenges of family's in relation to psychological, social, economic, sibling and marital impact of mental retardation on their families have the following implication for social work practice. The findings of the study show that measures at various levels aiming at reducing/eliminating the problem. Thus, the researcher wants to offer some recommendations with the suggestions that have been proposed by the participants of this study.

Family of Children with Mental Retardation: Developing and strengthening families' ties and social support network is essential to enable families to make an open discussion about the problem and to help each other. A strong social support network is often useful for the distressed person to release his/her negative feelings and frustration and to receive social support. The more social support an individual has, the better he or she is able to deal with stress [27].

Government and other concerned bodies:Mental retardation is not only a problem which affects the sufferer and their family members but also the society where they are living them. It affects a society both psychosocially and economical (development of the country). Thus, if we accept this reality, government and other concerned body should do tasks which could be remedy for it. The followings are some of the tasks by which the researcher of this study suggested for them.

Public Education: The government should give public education campaign to create awareness about the problem. It can do this action through mass media, workshops, counseling, etc. Both electronic media and press are appropriate instruments since they can address a number of people throughout the country. Workshops and counseling services can be organized and extended by concerned bodies to those who need the programs. In all forms of the programs, the target populations that need to be addressed include: governmental officials of various sectors and levels, potential employers from the government, non-government and private sectors, religious leaders, and other citizens.

This will changes the negative belief systems of the community towards the problem. The researcher speaks this confidently because we have success on HIV/AIDS, which had a great stigma and discrimination towards it.

Advocacy, lobbying and other initiatives: The lobbying and advocacy activities are more or less similar or can be part of that of awareness raising programs. This can be done by both government and other concerned body (e.g. NGOs).

Distributing the services:Government should expand its centers to different localities of the country.

Safeguarding the rights: Government also should work to protect of the rights of children with mental retardation.

Religious and other institutions:They should teach their fellows about the problem.

$N G O s$ : Even if the problem is creating this impact, in the researcher observation, there is only one NGO who is working on it. Thus, the researcher highly recommend for NGOs to work on it. Awareness programs to parents regarding "Mental Retardation" should be conducted by the both Government and NGO.

Researchers: In the light of these findings further research areas is recommended with the aim of using such information to build appropriate and successful rehabilitation and intervention programs for children with mental retardation. After these all, the concerned body should initiate follow up through conducting research in order for observing changes.

\section{REFERENCES}

[1] Abbaduto, L. (2003). Language and communication in mental retardation (International Review of Research in Mental Retardation, Vol. 27. 
[2] Abraham, H. (1998). Parental Perspectives on Mentally Retarded Children In Ethiopia: The Case of Addis Ababa

[3] Akrim, N., Ekehammar, B., Claesson,M., \&Sonnander, K. (2006). Classical and Modern Prejudice: Attitudes towards People with Intellectual Disabilities, Uppsala University.

[4] American Association on Mental Retardation. ( 2002). Mental Retardation

[5] American Psychiatric Association. (2000). Diagnostic And Statistical Manual Of Mental Disorders; Washington, DC Anonymous. (No Year). Disability Theory

[6] Aslam, Z. and Aslam, K., Hashmi,N., Batool,Z., \&Aslam,T.(2011). Socio-Psychological Problems and Needs of Mentally Retarded Children In Districts Faisalabad And Islamabad, Pakistan;Department of Rural Sociology, University of Agriculture, Faisalabad

[7] Bloor,M. \& Wood, F.(2006). Keywords in Qualitative Methods: A Vocabulary of Research Concepts,SAGE Publications;London Bruce L. Berg (2001).Qualitative Research Methods for Social Sciences $\left(4^{\text {th }} \mathrm{Ed}\right)$. California State University, Long Beach Berg: Allyn and Bacon Press

[8] Byrne, P. (2011). Stigma of mental illness and ways of diminishing it: Psychiatric Treatment.

[9] CherenetTekle,.Opdal, R.(2007). Raising a child with intellectual disabilities in Ethiopia: What do parents say? American Educational Research Association

[10] Child Assessment service. (2008). Mental Retardation: Department of Health, HKSAREthiopian National Association on Intellectual disabilities strategic Plan.( 2011).

[11] Creswell, J. W. (2009). Research Design: Qualitative, Quantitative, and Mixed Approaches. (3rd ed). Los Angeles: SAGE Publications.

[12] Creswell, J. W. (2012). Educational Research: planning, conducting, and evaluating quantitative and qualitative research, 4th ed. Boston, MA: Pearson.

[13] Creswell, J.W. (2014). Research Design: Qualitative, qualitative and mixed method approaches (4thed). New York: Sage publications Inc.

[14] Goswami, S. (2013). The Parental Attitude of Mentally Retarded Children:Global Journals Inc. (US)Davis, R. (No
Year). A Disordered Theory of Mental Retardation: Medical Psychological Laboratory, Cambridge University

[15] Govender, N.(2002). Attitudes of parents towards their Mentally retarded children: A ruralArea examination

[16] Kumar, A. \&Sharma,A.(2013).A Study to Assess the Disability Impact on Parents Of Children With Mental Retardation Studying In Two Special Schools Of Delhi

[17] McGrath, P. (2006). Psychosocial Issues in Childhood Autism Rehabilitation. A Review (Ed). International Journal of Psychosocial Rehabilitation. 11 (1), 29-36.

[18] Nema, B.(2000). Assessment of Adaptive Behavior of Some Children with Mental Retardation in Ethiopia: Addis Ababa University

[19] Padgett, D. K. (2008), Qualitative Methods in Social Work Research 2nd ed. New York Sage Publications, Inc.

[20] Padhye,V.(2012). Role of Gender and Education in Parental Attitude towards Mental Retardation:International Educational E-Journal, \{Quarterly\}, ISSN 2277-2456,Volume-I, Issue-IV

[21] Schalock,R., Luckasson,R.,Shogren,K.(2007). Intellectual and Developmental Disabilities:Vol.45, No. 2

[22] SenaitG/Medhin (2006). Comparative study of the psychosocial functioning of children with visual impairment in integrated and special need school setting, Unpublished MA thesis Addis Ababa University.

[23] SelamawitTadesse (2001). Child rearing practices by parents of children with physical disability, Unpublished MA thesis Addis Ababa University

[24] TehetenaWoldetensay (2010). Psychosocial experiences of children with repaired cleft lip and palate,Unpublished MA thesis Addis Ababa University.

[25] Thengal, N.(2013). Attitude of Parents and Family Members towards Their Mentally Retarded Children in Assam

[26] Tirusew, T (2005), Disability in Ethiopia: Issues, Insights and Implications. Addis Ababa University Printing Press, Addis Ababa.

[27] WHO (2004).World conference on special needs education: Access and quality needs Education .Salamanca Spain.0. 